\title{
A Heterogeneidade e suas Implicações para as Políticas Públicas no Rural Brasileiro ${ }^{1}$
}

Walter Belik ${ }^{2}$

Resumo: $\mathrm{O}$ artigo faz uma rápida revisão sobre os trabalhos que tratam da heterogeneidade da agricultura brasileira, demonstrando que essa é uma condição historicamente verificada no nosso meio rural e que pode ser encontrada em outras agriculturas, mais tecnificadas ou intensivas em mão de obra. Procura-se evidenciar que, mais que a heterogeneidade, a política pública deve voltar a sua atenção para a redução das desigualdades que têm suas causas ligadas ao acesso diferenciado aos fatores de produção e à baixa capacidade dos produtores em obter ganhos líquidos nas suas explorações. Recomenda-se a adoção de ações simples ligadas à assistência técnica, extensão rural, financiamento da produção e comercialização.

Palavras-chaves: Política agrícola, desenvolvimento rural, heterogeneidade.

Abstract: This article is a fast review on the heterogeneity of Brazilian agriculture debate. It was demonstrated that this is a historically verified condition in our rural areas and can be found in other agricultural sectors, more technical or more labor intensive. Beyond the heterogeneity, public policy must turn its attention to reducing inequalities that have their causes related to differential access to factors of production and the low capacity of the producers to obtain net gains from their holdings. It is recommended the adoption of simple actions related to technical assistance, extension, credit to produce and trade.

Key-words: Agricultural policy, rural development, heterogeneity.

Classificação JEL: Q01, Q18.

http://dx.doi.org/10.1590/1234-56781806-9479005301001

1. Corresponde à aula magna proferida por ocasião da abertura do $52^{\circ}$ Congresso da Sober, realizado em Goiânia (GO), em 2014

2. Professor Titular do Instituto de Economia da Unicamp. E-mail: belik@eco.unicamp.br 


\section{Introdução}

Nos últimos anos, a literatura sobre desenvolvimento rural no Brasil vem sendo marcada pela discussão sobre a heterogeneidade produtiva. Surgiram diversos estudos tratando das diferenças nos padrões produtivos do campo e a contribuição de cada um dos elementos para o crescimento da agropecuária. É interessante notar que, nesse esforço analítico, o foco não está mais na discussão sobre o dualismo da agricultura brasileira que contrapunha, entre outras estruturas, o latifúndio exportador à pequena propriedade de subsistência (RANGEL, 2005) o que levava Celso Furtado a afirmar que "não se poderia falar em desenvolvimento agrícola para o conjunto do país e sim tão somente de um crescimento em extensão da agricultura" (2009, p. 231). Da mesma maneira não estaria presente $o$ dualismo tecnológico constatado nos estudos da difusão induzida (PAIVA, 1971; SCHUH, 1973), pois o estoque de tecnologias e o crédito teriam se ampliado para dimensões consideráveis nas últimas décadas. Por outro lado, a visão de uma heterogeneidade estrutural da economia - um dos pilares do pensamento cepalino (SQUEFF e NOGUEIRA, 2013; CATELA e PORCILE, 2013) encontrou seu paralelo para o setor agrícola em alguns estudos que demonstram as diferenças na PTF (Produtividade Total dos Fatores) entre os diversos tipos de empreendimentos da agro- pecuária e de como essas assimetrias estariam se aprofundando.

O tema é bastante oportuno, pois, às vésperas de completarmos os Objetivos do Milênio estabelecidos para 2015, persistem ainda grandes diferenças de renda entre o campo e as áreas urbanas. No Brasil, essas desigualdades vêm diminuindo, de acordo com o Censo Demográfico de 2010 do IBGE ainda haveria 6,2 milhões de pessoas ou 2,2 milhões de domicílios rurais abaixo da linha da pobreza de $\mathrm{R} \$ 70,00$ mensais per capita ${ }^{3}$. Contudo, apesar de já termos atingido antecipadamente os Objetivos do Milênio a proporção de pobres no campo em relação à sua população é quase seis vezes maior que aquela que se observa nas áreas urbanas. Em termos mundiais, considera-se que os objetivos de redução da extrema pobreza já foram atingidos em função do enorme progresso alcançado pela China nas duas últimas décadas. Esse país reduziu a extrema pobreza de 42,5\% da sua população rural de 1990 (CHEN e WANG, 2001) para apenas 10,2\%, segundo informações de 2012 do Banco Mundial ${ }^{4}$. Todavia, os dados otimistas sobre os progressos na luta contra a desigualdade em todo mundo permitem ape-

3. Estabelecida pelo Programa Brasil Sem Miséria para 2010 e correspondente aos valores aproximados de US\$1,25 per capita/dia, em poder de compra, estabelecidos pelo Banco Mundial.

4. The World Bank - Poverty and Inequality Database. 
nas reduzir o impacto do fato de que mais $70 \%$ da pobreza ainda estão domiciliados no campo ${ }^{5}$.

O ano de 2014 foi escolhido também pela Organização das Nações Unidas para Agricultura e Alimentação (FAO) como o Ano Internacional da Agricultura Familiar, sendo que a sua mais importante publicação - o State of Food and Agriculture desse ano trata da Inovação na Agricultura Familiar como alavanca para a redução das desigualdades no campo. Analisando-se as estatísticas internacionais, observa-se que nove entre dez produtores da agropecuária no mundo se enquadram na categoria de estabelecimentos familiares e a FAO acredita que esse setor é fundamental para garantir a produção dos alimentos e matéria-prima. Alimentos esses que serão necessários para abastecer um mundo de 9,1 bilhões de habitantes em 2050, sem pressões adicionais sobre a terra e o consumo de água, além de garantir a biodiversidade sobre o planeta. Utilizando as 36 definições oficiais de agricultura familiar que são encontradas ao redor do mundo, a FAO estima que haveria em torno de 500 milhões de unidades de produção familiar trabalhando $70 \%$ da terra utilizada na agropecuária e produzindo $80 \%$ dos alimentos da humanidade (FAO, 2014). $\mathrm{O}$ reconhecimento dessa agricultura como um universo e não como uma categoria em transição já dá a necessária dimensão para abordagem da heterogeneidade.

\section{Aspectos históricos comparativos}

Em artigo recente, Long e Ploeg (2011) chamavam a atenção para a armadilha teórica das análises baseadas na heterogeneidade na agricultura. Diziam os autores que as principais correntes do desenvolvimento rural, a teoria da modernização e a teoria marxista, teriam buscado mostrar a inexorabilidade do desenvolvimento em direção a um mundo rural mais homogêneo. Em

5. Segundo Alkire et al. (2014), da Oxford Poverty \& Human Development Initiative, as porcentagens de pobreza rural atingiriam $83 \%$ para os indicadores de pobreza multidimensional coletados em 105 países. resumo, a teoria da modernização teria vislumbrado a possibilidade de incorporação generalizada do progresso técnico entre os produtores e a sua consequente disseminação, que empurraria a agricultura para um paradigma cada vez mais tecnificado, dado que o ambiente competitivo iria paulatinamente homogeneizar o uso de fatores, reduzindo também as diferenças de rendimento. Já as teorias marxista e neomarxista, por sua vez, tomariam a expansão do capitalismo monopolista e seu padrão de produção dominante como hegemônico, o que acabaria envolvendo formas mais atrasadas de produção, homogeneizando, da mesma maneira, a organização da produção no meio rural.

Representações à parte, pois evidentemente todos os modelos têm as suas nuances, esses modelos deterministas subestimariam o poder de persistência das formas de organização da produção e também a sua capacidade de competir nos espaços globalizados. Evidentemente, os autores mencionados reconhecem essas especificidades e se referem à coexistência de diversos estilos de agricultura - mais mercantilizados ou mais autônomos, o que provocaria efeitos diferentes nesses grupos a partir da introdução de uma nova tecnologia ou da política pública.

Historicamente, talvez pudéssemos identificar no Brasil colonial certa homogeneidade na agricultura consubstanciada no sistema de "plantation" que se caracteriza pela grande propriedade, trabalho escravo e monocultura (PRADO JUNIOR, 1961). Todavia, como mostram os estudos (PAIM, 1957; PRADO JUNIOR, 1970),com a renascimento da agricultura nos finais do século 18,o Brasil estaria dividido em diferentes áreas de produção quase que autônomas e autossuficientes, ou sistemas de produção que denominamos de complexos rurais (KAGEYAMA, 1990). Outro detalhe interessante é que, lado a lado com o latifúndio exportador haveria uma pequena produção de alimentos dinâmica que contrastava diretamente com a monocultura em outros tipos de estrutura agrária. Essa produção era voltada para a oferta de alimentos voltada aos aglomerados urbanos que se formavam e já produzia 
tendo como base a mão de obra servil e mais tarde, imigrante e assim como os escravos libertos. Para ilustrar a importância e as proporções do mercado consumidor servido por essa produção, basta destacar que no auge do ciclo do café, no ano de 1900, a cidade de S. Paulo contava com 240 mil habitantes, a capital, Rio de Janeiro, com 522 mil habitantes, Salvador, com 174 mil e Recife, com 113 mil habitantes.

A construção do primeiro Mercado Central de Alimentos em S. Paulo, que termina em 1867, demonstra que de fato existia um local físico, um mercado de alimentos constituído, para um espaço urbano que já necessitava de uma certa ordenação. Por volta dessa época, a agricultura de alimentos se descola do café em S. Paulo e a produção de alimentos e matérias-primas fora das fazendas de café e não vinculada ao regime de colonato dispara (DEAN, 1971). Segundo Wilson Cano (1981), "o satisfatório desempenho da agricultura paulista, por outro lado, proporcionava grande parte do suprimento à sua força de trabalho, e garantia o abastecimento local de matérias-primas à indústria nascente" (p. 228), como é o caso do algodão do Sul, Minas Gerais e do Nordeste, suprindo a demanda de insumos da infante indústria têxtil.

No que se refere aos gêneros básicos consumidos pela população, além das chácaras próximas dos grandes centros que forneciam alimentos para serem vendidos nas feiras, armazéns de secos e molhados e nas quitandas, havia uma produção comercial (além dos limites do latifúndio) de gêneros como o milho, feijão, arroz e charque. Tudo isso era produzido em propriedades "familiares" que se diferenciavam em muito do setor exportador a que os pesquisadores geralmente se referem como "a" agricultura brasileira.

No início do século 20, ao lado da conhecida agricultura de subsistência, existia um setor de produção de alimentos voltado para o abastecimento das cidades e para a exportação. $\mathrm{O}$ dinamismo desse segmento era notório e, com a eclosão da I Guerra Mundial, o Brasil passou a fornecer alimentos para a Europa, deixando desabastecido o mercado interno (LINHARES e TEIXEIRA da SILVA, 1979). Na cidade de S. Paulo, que havia quadruplicado a sua população em uma década, a agitação social tomava conta das ruas e, ao mesmo tempo, tensões são registradas no Rio de Janeiro e em outras capitais, exigindo que o governo central impusesse pela primeira vez na história, ainda que de forma provisória, leis de intervenção direta no mercado de alimentos contra a carestia.

Em termos internacionais, essa heterogeneidade também está presente. As desigualdades em termos de tamanho de área, aporte tecnológico, gestão e utilização da força de trabalho são enormes quando comparamos as diferentes regiões e países. Mesmo entre os agricultores familiares as diferenças são significativas. Existem 36 diferentes definições de agricultura familiar entre as legislações dos países e, considerando as mais de 570 milhões de unidades de produção agropecuária no mundo todo, os familiares devem representar mais de 500 milhões desse total (HLPE, 2013; FAO, 2014). Em levantamento realizado junto a 81 países (cobrindo $2 / 3$ da população e $38 \%$ da terra arável do mundo) o HLPE concluiu que $72,6 \%$ das unidades de produção familiares possuem menos de 1 ha (HLPE, 2013)

Em excelente trabalho de organização de informações sobre a agricultura familiar, Leporati et al. (2014) demonstram as diferenças enormes entre as áreas médias dos estabelecimentos na América Latina e no Caribe. Como se pode observar no Quadro 1, a área média dos estabelecimentos da agricultura familiar no Brasil é de 24 ha, na Argentina, 107 ha e, no Cone Sul como um todo, de 47 ha. Também podemos comparar o Cone Sul com a América Central e México com 3 ha ou com os Andinos também com médias em torno de 3 ha. Contudo, o mais surpreendente é a razão entre as médias de tamanho do familiar com o não familiar. Se compararmos as áreas médias, percebe-se que a área média de um estabelecimento de agricultura em geral comparado com um familiar é de 2,5 vezes no Brasil. $\mathrm{Na}$ Argentina, essa diferença chega a cinco vezes 
Quadro 1. Superfície e tamanho médio das explorações no setor agropecuário e na agricultura familiar na América Latina e Caribe, segundo sub-região e países selecionados

\begin{tabular}{|l|c|c|c|}
\hline \multirow{2}{*}{ Sub-região/países } & Setor Agropecuário (ha) & Agricultura Familiar (ha) & \multirow{2}{*}{ Relação entre médias } \\
\cline { 2 - 4 } & Média por exploração & Média por exploração & $\mathbf{4 , 2}$ \\
\hline Todos os Países da Região & $\mathbf{5 7 , 7}$ & $\mathbf{1 3 , 6}$ & $\mathbf{1 , 9}$ \\
\hline Caribe & $\mathbf{2 , 6}$ & $\mathbf{1 , 3}$ & 2,7 \\
\hline Antígua e Barbados & 1,2 & 0,4 & 5,3 \\
\hline Jamaica & 1,6 & 0,3 & 2,7 \\
\hline Santa Lucia & 1,3 & 0,5 & 1,5 \\
\hline Suriname & 6,3 & 4,1 & $\mathbf{4 , 4}$ \\
\hline América Central + México & $\mathbf{1 3 , 9}$ & $\mathbf{3 , 1}$ & 5,3 \\
\hline Guatemala & 6,4 & 1,2 & 3,6 \\
\hline México & 24,3 & 6,8 & 8,0 \\
\hline Panamá & 10,9 & 1,4 & $\mathbf{6 , 2}$ \\
\hline Andinos & $\mathbf{1 9 , 1}$ & $\mathbf{3 , 1}$ & 5,6 \\
\hline Colômbia & 25,1 & 4,5 & 4,2 \\
\hline Equador & 14,7 & 3,5 & 13,6 \\
\hline Peru & 17,5 & 1,3 & $\mathbf{4 , 1}$ \\
\hline Cone Sul & $\mathbf{1 9 5 , 1}$ & $\mathbf{4 7 , 0}$ & 4,9 \\
\hline Argentina & 524,2 & 107,5 & 2,6 \\
\hline Brasil & 63,8 & 24,2 & 1,8 \\
\hline Chile & 85,0 & 46,0 & 10,3 \\
\hline Paraguai & 107,3 & 10,5 & \\
\hline
\end{tabular}

Fonte dos dados brutos: Leporati et al. (2014).

e no Paraguai, a dez vezes. Nesse caso, apenas comparando as médias, a nossa heterogeneidade entre tipos de agricultura está mais parecida com aquela observada no Caribe que a realidade do Cone Sul.

A heterogeneidade também está presente em países como a Índia, que se caracteriza por uma grande massa de microprodutores e de grandes fazendas monocultoras. Na China, onde os direitos de propriedade da terra pertencem ao Estado, poderia ter se preservado maior simetria na produção; porém, com o fim do sistema de produção coletivo, o aumento na desigualdade ocorreu de forma preocupante. Para o caso chinês em particular, verifica-se que a diferença nas rendas entre as províncias do sudeste da China, onde começaram as reformas econômicas, e as províncias Ocidentais, estaria de 2 a até 4 vezes (FAN e SUN, 2008). Na realidade, e surpreendentemente, a diferença de rendas rural - rural é muito maior que a diferença urbano - urbano (RAVAILLON, 2013).
Nos Estados Unidos, por sua vez, o idílico modelo de ocupação agropecuária conhecido como "homestead", que se disseminou com os pioneiros colonizadores, já não é mais o padrão para o campo. Segundo os dados do USDA (Departamento de Agricultura dos Estados Unidos), em 2011, 17\% dos residentes no campo estavam abaixo da linha da pobreza, sendo que essa vem crescendo desde meados da década passada, enquanto a propriedade da terra vai se concentrando. Atualmente, segundo dados mais recentes do Censo Agropecuário (2012),as fazendas acima de 2.000 acres (aproximadamente $400 \mathrm{ha}$ ) representavam $1,4 \%$ do total, mas detinham $55,5 \%$ da área. Já as fazendas com até 49 acres representam $32,4 \%$ do total, detendo apenas 1,7\% da terra agricultável. Há 40 anos, em 1974, as fazendas com mais de 2.000 acres eram $2,6 \%$ e detinham $45,9 \%$ das terras. Já as fazendas no limite de até 49 acres representariam $21,9 \%$ do total, com volume de terras equivalente a apenas $1,1 \%$. 


\section{A heterogeneidade e a agricultura brasileira}

Segundo o Censo Agropecuário de 2006, haveria no Brasil 5,1 milhões de estabelecimentos com enormes diferenças entre as características regionais, condição legal das terras, condição do produtor, tipo de atividade etc. Grandes debates têm sido travados sobre a forma de fazer o recorte específico da agricultura familiar nesse universo, ao qual ingenuamente se atribui algum tipo de homogeneidade. O ponto de partida é a discussão sobre as fronteiras desse grupo. Segundo o IBGE, os agricultores familiares representariam $84,3 \%$ dos estabelecimentos (IBGE, 2006), enquanto que, segundo a metodologia FAO-Incra desenvolvida por Guanzirolli e colaboradores, a participação subiria para $87,9 \%$ (GUANZIROLL, BUAINAIN e SABATO, 2012) e segundo a metodologia da CNA/FGV, que desconsidera 1,3 milhão de estabelecimentos sem renda e também toma os critérios mais restritos do Pronaf (Programa Nacional de Fortalecimento da Agricultura Familiar), esses domicílios não passariam de 64\% do universo (FGV, 2010). O Quadro 2 ilustra essas diferenças de tamanho e a participação relativa dos agricultores familiares.

Para esse grande grupo de agricultores familiares, Schneider e Cassol (2013) desenvolveram um recorte interessante para diferenciar os tipos de produtores analisando outros aspectos além da área. Tomou-se como base a receita agropecuária, buscando diferenciar os produtores segundo a sua origem, e os produtores foram separados segundo a importância das receitas agropecuárias para a receita total do estabelecimento: pouca importância (menos de 20\%) - considerando que o estabelecimento é um local de moradia; grande importância (maior de 51\%) - considerando que esse estabelecimento é especializado, e uma situação intermediária, demonstrando que o estabelecimento tem múltiplas fontes de renda. Vale mencionar que nesses recortes não foram considerados os estabelecimentos sem renda. Observa-se, então, a diferença que existe em termos do número de estabelecimentos separando-se os familiares (cuja predominância é de trabalho familiar) com os não familiares. A maioria dos produtores é de especializados, seja para o caso dos familiares como nos não familiares, mas existem mais de $25 \%$ dos estabelecimentos que não declararam renda seja porque eram ineficientes, não quiseram declarar ou porque, devido às características da sua atividade (pecuária ou silvicultura, por exemplo), não auferiram renda naquele ano. Além disso, o mais importante é que certas rendas e participações dos integrantes da família não foram consideradas nas rendas do estabelecimento, o que deixa de fora uma série de rendas importantes como as aposentadorias, por exemplo.

Os dados compilados por Schneider e Cassol (2013) mostram também que haveria grande quantidade de assentados nesse total de produtores familiares. Segundo levantamentos, existiriam mais de 575 mil assentamentos no Brasil nesse ano (12\% do total de estabelecimentos), sendo que boa parte deles, por estarem na fase de instalação, não possuem renda - o que vem sendo reforçado pelo fato de que quase metade desses estabelecimentos sem renda possui menos

Quadro 2. Delimitações da agricultura familiar a partir do Censo Agropecuário de 2006 - Brasil

\begin{tabular}{|c|c|c|c|c|}
\hline \multirow{2}{*}{ Metodologia } & Variável & $\begin{array}{c}\text { Número de } \\
\text { Estabelecimentos }\end{array}$ & $\begin{array}{c}\text { Área Total } \\
\text { (milhões de ha) }\end{array}$ & $\begin{array}{c}\text { Valor Bruto da Produção } \\
\text { (R\$ bilhões) }\end{array}$ \\
\hline \multirow{2}{*}{ FGV } & valor & 3.330 .067 & 59,4 & 32,8 \\
\cline { 2 - 5 } & $\%$ & 64,0 & 18,0 & 22,9 \\
\hline \multirow{2}{*}{ IBGE } & valor & 4.367 .902 & 80,3 & 54,3 \\
\cline { 2 - 5 } & $\%$ & 84,3 & 24,3 & 37,8 \\
\hline \multirow{2}{*}{ FAO/ Incra } & valor & 4.551 .855 & 106,7 & 59,2 \\
\cline { 2 - 5 } & $\%$ & 87,9 & 32,0 & 36,1 \\
\hline
\end{tabular}

Fonte dos dados brutos: IBGE (2006), FGV (2010) e Guanzirolli, Buainain e Sabbato (2012). 
de 20 ha e produzem quase que exclusivamente para autoconsumo. Em outras palavras, não são estabelecimentos improdutivos, mas as estatísticas, quando vistas à distância, não conseguem destacar essas particularidades.

A área média dos estabelecimentos familiares dos três tipos é muito semelhante, portanto, não é o tamanho da unidade de exploração que explica as diferenças de inserção de atividades produtivas entre os familiares. Já a produção para o autoconsumo é uma variável diferenciadora importante; nos estabelecimentos de residentes rurais, a produção para o autoconsumo está presente em 58\%; nos estabelecimentos, naqueles com múltiplas fontes de rendimento, o autoconsumo está presente em apenas $32 \%$ e, finalmente, nos especializados, o autoconsumo aparece em apenas $20 \%$ dos casos. Essa observação é importante quando tratarmos das políticas. $\mathrm{O}$ autoconsumo vai desaparecendo na medida em que os estabelecimentos vão se especializado e a renda vai aumentando. Outro fator que chama a atenção é o acesso à assistência técnica, que é muito pequeno e corre no sentido inverso dessa tipologia, com 7,8\% dos residentes rurais tendo esse acesso, $14 \%$ e $28 \%$, respectivamente, para o caso estabelecimentos com múltiplas atividades e dos especializados.

Essas diferenças também podem ser detectadas quanto ao destino da produção. Boa parte da produção familiar de lavouras temporárias é utilizada como consumo intermediário do estabelecimento. No caso da agricultura familiar especializada, mais de $80 \%$ do valor da produção não entra no mercado, sendo utilizado nos estabelecimentos. No caso das lavouras permanentes, a produção vai ao mercado e o principal canal de escoamento da produção são os agentes intermediários, variando segundo o grau de especialização do estabelecimento. Outra grande diferença se apresenta quanto aos indicadores de produção, composição das receitas e acesso aos serviços de assistência técnica. Quando comparamos o total das receitas (incluindo a receita imputada de autoconsumo), observa-se que os residentes rurais tinham uma renda mais de 20 vezes menor que os estabelecimentos especializados e que a renda dos produtores com múltiplas receitas era 10 vezes menor que os especializados.

Outra maneira de demonstrar a grande heterogeneidade e diferenciação entre os agricultores familiares é através do destaque feito a partir da utilização da força de trabalho. Kageyama, Bergamasco e Ayer de Oliveira (2013), tendo como base o Censo Agropecuário de 2006 do IBGE, separaram os produtores em familiares (predominância de mão de obra familiar) e não familiares, sendo que os familiares ainda seriam subdivididos em assentados, exclusivamente familiares e familiares com pessoal contratado. Observa-se, então, grande diferença entre as categorias, mas as autoras afirmam que o maior foco de desigualdade estaria dentro de cada um dos grupos analisados e não entre os grupos. Por exemplo, no grupo dos agricultores familiares com empregados contratados, $14,3 \%$ dos estabelecimentos têm mais de 100 ha, contribuindo com quase $80 \%$ da área total, sendo que esses contribuem com $43,2 \%$ do Valor Total da Produção (VTP) dos estabelecimentos dessa classe. No grupo exclusivamente familiar, as diferenças também são enormes. Lá existem estabelecimentos com mais de 100 ha $(5,2 \%)$ e eles contribuem com $64,1 \%$ da área e ficam com 29,5\% do VTP da categoria (Figura 1). 
Figura 1. Brasil: Distribuição dos estabelecimentos da agropecuária por área e por tipo

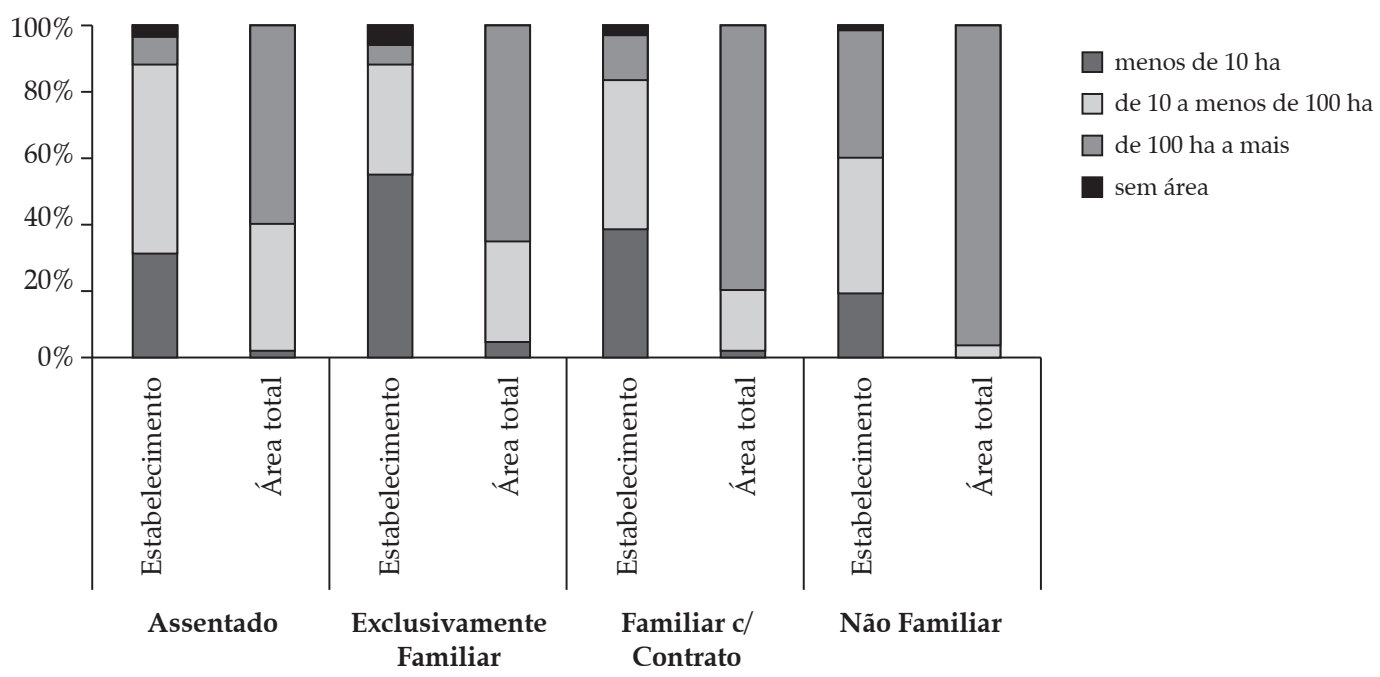

Fonte dos dados brutos: Kageyama, Bergamasco e Ayer de Oliveira (2013).

Não é a origem da renda dos produtores que estabelece a forma de diferenciação para os agricultores brasileiros. Tanto os estabelecimentos de agricultores familiares como os dos não familiares têm mais de $90 \%$ da sua receita derivada das atividades da agropecuária. Essa situação se diferencia do que acontece na Europa, onde $12 \%$ dos estabelecimentos estão envolvidos com atividades rentáveis fora das fazendas - sendo que, em países como a Alemanha, França e Grã-Bretanha, essa porcentagem chega a $25 \%$, e essas ocupações recebem pleno suporte da Política Agrícola Comum (PAC), pela qual, aproximadamente $45 \%$ dos recursos da PAC são dirigidos ao Desenvolvimento Rural (EUROPEAN COMMISSION, 2008). Nos Estados Unidos, as estatísticas do Censo Agropecuário de 2012 indicam que, no total, aproximadamente $15 \%$ da renda das fazendas é derivada do agroturismo, atividades recreativas, produção sob encomenda e outros serviços.

No Brasil, mesmo entre os pequenos produtores a receita derivada de outras atividades é inexpressiva (8,7\% em média, 16,6\% para o exclusivamente familiar), muito embora essa renda de Pessoa Física conte com uma grande participação das aposentadorias e assalariamento (KAGEYAMA, BERGAMASCO e AYER DE OLIVEIRA, 2013). Na Europa, 36,4\% dos produ- tores estão alocados em atividades não agrícolas, sendo que, para aqueles que trabalham nas menores fazendas (entre 0 e $2 \mathrm{ha}$ ), a proporção chega a 41,5\% (EUROPEAN COMMISSION, 2008).

Muito embora não seja visível a diferenciação dos produtores, existe uma série de determinantes que levam à esta dentro de cada categoria na agricultura brasileira. Por exemplo, o fato de o chefe de família do domicilio do meio rural trabalhar principalmente na agricultura explica a maior incidência de pobreza para essas famílias, em comparação com o caso de o chefe desenvolver o trabalho em outras esferas. Outro ponto importante é a posição na ocupação daqueles que trabalham na agricultura. Mesmo dentre aqueles chefes de família cuja atividade principal é a agricultura, a incidência de pobreza é maior entre os empregados que entre os conta-própria ou empregadores (HELFAND e DEL GROSSI, 2009).

\section{Heterogeneidade e a Produtividade Total dos Fatores (PTF)}

A incorporação da PTF como indicador de heterogeneidade é mais abrangente que a simples análise do tamanho da propriedade, mas esse tipo de abordagem enseja que se leve em 
conta também os elementos que influenciam nessa PTF, como é o caso da educação, a capacidade de investimento e o nível de renda dos produtores. A maior produtividade dos fatores pode representar renda mais elevada para os estabelecimentos e essa pode levar também a um maior aporte de terras, de capital produtivo e de capital humano, o que representa vantagem a cada novo ciclo produtivo. Helfand e Pereira (2012) mostram que a insuficiência de terras (estrutura agrária) é um fator de redução de renda importante. Aumentos na quantidade de terra entre décimos, ou aplicando uma análise contrafactual - utilizando, por exemplo, a estrutura agrária da região Sul no Nordeste, demonstram que seria possível reduzir a pobreza rural, mantendo-se a mesma PTF e alterando-se a função de produção.

Outro fator importante é o capital humano. Mais anos de estudo melhoram a renda do estabelecimento, e os dados do Censo Agropecuário 2006 mostram grandes diferenças nos anos de permanência na escola entre jovens rurais e urbanos. Como se sabe, os rurais entram mais tarde na escola e abandonam mais cedo. A partir dos 13 anos aumenta o abandono e poucos jovens rurais vão para o Ensino Médio. Com 16 ou 17 anos, a diferença entre urbanos e rurais sobe para $10 \%$ na frequência escolar, e efetivamente com 17 anos de idade, $35 \%$ dos jovens rurais não estavam na escola.

Quanto ao acesso ao capital, há vários problemas. Sabemos que há mais dificuldades para acesso ao crédito por parte da Agricultura Familiar, mas os dados do Censo mostram que, surpreendentemente, a porcentagem de estabelecimentos que não obteve financiamento no segmento familiar é muito semelhante ao observado pela agricultura não familiar em 2006. Os resultados mostram proporção de $81,1 \%$ e $81,3 \%$ na comparação entre o familiar e o não familiar. $\mathrm{O}$ problema é que o crédito para a agricultura familiar está concentrado na região Sul, com mais de $60 \%$ do crédito privilegiando a categoria de proprietários da agricultura familiar. O Nordeste, que teria 50,8\% dos estabelecimentos da Agricultura Familiar, recebe apenas $26 \%$ do crédito, sendo que no início do Pronaf, em 1996, o Nordeste recebia apenas $6,6 \%$ desse total. O valor dos contratos também varia muito de acordo com a localização e o porte do estabelecimento (BELIK, 2014).

A partir das medidas de produção da agropecuária e do uso de insumos, os trabalhos do José Garcia Gasques e associados (GASQUES et al., 2012) demonstram que, entre 1975 e 2011, a produção cresceu a taxas médias anuais de $3,7 \%$ e teve como componentes um aumento de 3,5\% na produtividade dos fatores e $0,2 \%$ ao ano no uso de insumos. Daí se conclui que $90 \%$ do aumento da produção poderiam ser creditados à PTF e apenas $10 \%$, ao aumento nos insumos nesses 37 anos. As variações na PTF podem ser atribuídas, por sua vez, a dois fatores: incorporação de progresso tecnológico e à inovação institucional. Alguns estudos dos autores mostram inclusive que, no que se refere ao progresso tecnológico, a atividade de pesquisa seria responsável por $30 \%$ do crescimento observado. A distribuição da produtividade entre os diversos estados da federação é um fator distintivo no que tange a heterogeneidade da agricultura brasileira. De fato, se analisarmos os dados da PTF no comparativo dos dois últimos Censos Agropecuários para os estados, vamos perceber enormes diferenças: $\mathrm{O}$ estado do Espírito Santo teve crescimento de 9,5\% a.a, Rondônia, 4,6\% a. a., mas Tocantins cresceu negativamente: $3,6 \%$ a.a. tendo como base os anos do Censo Agropecuário (GASQUES et al., 2010).

Como se comportou a PTF no segmento da Agricultura Familiar ao longo desses anos? A hipótese corrente seria de que os estabelecimentos da Agricultura Familiar incorporam pouca terra e utilizam poucos insumos modernos, o que faria concentrar a PTF apenas no fator mão de obra e, por consequência, os ganhos de produtividade acabariam por ser reduzidos. Sabemos que, por problemas metodológicos, a comparação da agricultura familiar entre Censos é muito difícil, mas, em um trabalho recente de Vieira Filho e Rosa dos Santos (2014), os pesquisadores conseguiram analisar a PTF usando somente o Censo de 2006. Para tanto, desenvolveu-se uma metodologia na qual se calcula a produtivi- 
dade dos fatores usando receitas e despesas do estabelecimento.

O resultado mostra que $57,6 \%$ dos estabelecimentos de agricultura familiar teriam a PTF abaixo de 1, ao mesmo tempo em que $67,7 \%$ dos estabelecimentos patronais também teriam a PTF abaixo de 1 . Com isso, no total, $60 \%$ dos estabelecimentos da agricultura brasileira teriam PTF abaixo de uma unidade, ou seja: renda líquida negativa (VIEIRA FILHO e ROSA de SOUZA, 2014). Em outras palavras: esses estabelecimentos seriam inviáveis. Outro dado curioso desse trabalho é que existem produtores familiares com alta produtividade e tecnificação superando os índices de produtividade dos produtores patronais mais capitalizados. Por exemplo, para a média dos patronais com alta incorporação de tecnologia, temos uma Produtividade da Terra, medida em Receita Bruta por hectare de R\$ 1.907. Já a Produtividade da Terra dos familiares de alta incorporação tecnológica é de R 2.571 (dados de 2006). Da mesma maneira, a Receita Bruta dividida pelo Gasto com Trabalhador nos Familiares é quase 4 vezes maior que a dos Empresariais, quando medimos pelo valor gasto com o trabalhador. Esse indicador serve de argumento para que se retomem as teses "chayanovianas" sobre o aumento da intensidade do trabalho nas unidades familiares e a autoexploração do campesinato. $\mathrm{O}$ indicador demonstra também que a dinâmica da produção na agricultura familiar não tem nada da visão idílica e fantasiosa que equivocadamente atrai reacionários e revolucionários. Estudo mundial da FAO (2014, p. 33) comprova essa hipótese mostrando que, em termos físicos, o rendimento por hectare é mais elevado nas unidades da agricultura nos países de baixa e média renda, mas a produtividade por trabalhador é menor. Isso é evidente dado que a densidade de trabalhadores por hectare é muito maior no caso da agricultura familiar. Como vimos, a produtividade do trabalhador é baixa na agricultura familiar - embora a renda por hectare seja alta, não só porque há uma baixa intensidade tecnológica, mas também, e principalmente porque há um excesso de mão de obra nas unidades familiares. Por esse motivo, temos que analisar as oportunidades de trabalho e de renda não só para dentro da porteira, mas também para fora, levando-se em conta o potencial dos rendimentos não agrícolas.

Uma política de aumento da renda rural que seja sustentável - em termos econômicos, sociais e ambientais, deve buscar aumentos de produtividade nos fatores de produção em detrimento de maior aporte nesses mesmos fatores ${ }^{6}$. A sustentabilidade é uma questão fundamental para o desenvolvimento rural, políticas que buscam aumento de produtividade com base em maior utilização de recursos naturais, ou maior quantidade de insumos - ainda que fossem de base orgânica não seriam sustentáveis ${ }^{7}$. Por outro lado, aumentos de produtividade, com intensificação do uso de fatores, podem ou não levar a aumentos de renda. Sabemos que o uso intensivo de insumos e capital pode acarretar em problemas ambientais no médio e longo prazo, impactos negativos na saúde dos trabalhadores e na organização do negócio familiar (PIMENTEL et al., 1977; GODFRAY et al., 2010; FOLEY et al., 2011; IFAD, 2013). Ademais, é preciso ter claro que os mercados não são perfeitos e, portanto, não é possível estimar com segurança a resposta dos preços em períodos futuros e os custos de transação que envolvem escalas maiores de produção (ZEZZA e LLAMBI, 2002).

Normalmente, se apresenta a alternativa do aumento da produção agrícola como a principal saída da pobreza no meio rural. Mas, em 2008, no Relatório para o Desenvolvimento Econômico, o Banco Mundial passou a admitir a possibilidade de três estratégias isoladas ou combinadas para

6. Há vasta literatura focada nos aumentos da produtividade dos fatores, redução dos hiatos produtivos entre as unidades, gerando, com isso, a redução da heterogeneidade entre os produtores. Nesse sentido, é muito comum observarmos trabalhos que projetam a redução dos "gaps", intensificando o uso de insumos em unidades inferiores com evidentes aumentos de renda (RAY et al., 2013, FAO, 2014).

7. Bernstein (2013) destaca que o discurso da sustentabilidade pode representar uma armadilha do discurso do "greening" (esverdeamento) do agronegócio - retirando umas das principais bandeiras do movimento ambientalista (p. 17). 
a saída da pobreza rural: aumentos de produtividade na agricultura, pluriatividade do trabalho e migração (BANCO MUNDIAL, 2007). Essas estratégias abrem o leque de possibilidades, indo mais além dos ganhos através da PTF que podem e devem ser combinados com estratégias que possam elevar a renda do domicílio rural e o bem-estar das pessoas que vivem nesse meio. Nesse sentido, a inovação deve ser vista não como um elemento atuante na esfera dos produtos e processos, mas também no formato de inovações organizacionais e sociais que podem ser introduzidas por meio de redes de atores (indivíduos e organizações) que interagem em um amplo processo de aprendizado.

As mudanças técnicas e organizacionais que estamos mencionando podem levar ou induzir a mudanças institucionais mais profundas (como, por exemplo, a legislação sobre direitos de propriedade) e essa mudanças institucionais, por sua vez, podem criar um ambiente mais propício à inovação e à adoção de novas tecnologias e novos formatos organizacionais. Mas a mudança técnica e organizacional não depende apenas do agricultor pobre, esta passa também por outros atores situados ao longo da cadeia produtiva. Nesse sentido, o grande negócio (empresas líderes) tem papel fundamental no sentido de induzir novas técnicas, apoiar as comunidades e também nos esquemas de comercialização.

No caso dos agricultores familiares de baixa renda, parece claro que uma forma direta que poderia garantir a sua viabilidade seria aumentar o aporte dos fatores, dando forma a empreendimentos que não conseguem crescer devido às suas limitações de área e disponibilidade de capital. Respeitadas as condições de sustentabilidade, em um segundo momento, esses investimentos, combinados com a mão de obra residente, poderiam produzir os ganhos de produtividade desejados. De fato, a impossibilidade de aumento do tamanho das pequenas propriedades poderia ser um problema em países como a Índia e a China (respectivamente com $61 \%$ e $94 \%$ das propriedades com menos de 1 ha (BELIERES et al., 2014), mas no caso do Brasil há muita terra que pode- ria ser incorporada ao sistema produtivo e isso reafirma a necessidade de não abandonarmos o debate sobre a questão agrária.

Como se observa nos dados do Censo Agropecuário de 2006, o índice Gini Fundiário continua estacionado no patamar de 0,85 há30 anos e a área referente aos $50 \%$ menores estabelecimentos não passa de $2,3 \%$ da área total. Nas regiões de fronteira agrícola o modelo das grandes propriedades se mantém, mas, ainda assim, "o Brasil possui nada menos que $15 \%$ das terras agricultáveis não exploradas no mundo" (FERREIRA, 2014, p. 9). O modelo de expansão do agronegócio no Brasil para novas áreas vem produzindo riquezas, mas a condição de bem-estar dessas populações é relativa. Como a pecuária extensiva e, em seguida, a soja, são culturas que demandam pouca mão de obra (a soja, por exemplo, é intensiva em capital), o resultado são municípios com boa arrecadação de impostos e nos quais circula muita riqueza. Também não se observa bolsões de pobreza, como havia no passado nas áreas de expansão da agricultura, fazendo com que os indicadores sociais desses municípios sejam elevados, muito embora esses não possam se constituir em exemplos de progresso.

Em outras palavras, há enorme vulnerabilidade nessas economias locais dadas a concentração da produção e a elevada área dos estabelecimentos. A desigualdade fundiária no Brasil se mantém como um dos fatores de desequilíbrio social no campo. Tomando-se os 10 melhores municípios segundo o IDR (Índice de Desenvolvimento Rural) desenvolvido pela CNA (Confederação Nacional da Agricultura) e pela FGV (Fundação Getúlio Vargas) ${ }^{8}$, e fazendo uma associação dos mesmos com o Índice de Gini Territorial e à Densidade Demográfica Rural, podemos observar que os melhores IDRs estão

8. Esse índice foi desenvolvido em 2013 e calculado a partir de informações do Censo Agropecuário de 2006 e do Censo Demográfico de 2010 e leva em conta as dimensões econômica, social, ambiental e demográfica com ponderações distintas (Relatório IBRE - FGV. "Índice de Desenvolvimento Rural (IDR): um Retrato dos Municípios Brasileiros") disponível em www.agricultura.gov.br/arq editor/file/.../App_CNA_Credito.pdf 
em municípios com altíssima concentração fundiária cuja densidade populacional rural está abaixo da unidade ou ligeiramente acima dela - ou seja, nove vezes menor que a média brasileira (RAMOS, 2014). Tirando-se dessa lista o município de Uberaba, que teve uma ocupação mais antiga, todos os municípios têm relação acima de 100 hectares por pessoa ocupada no campo. Chama a atenção também o município de Telêmaco Borba no Paraná, onde está instalada uma gigantesca unidade de fabricação de celulose e está classificado entre os 10 melhores IDRs do Brasil. O Gini Territorial desse município é de 0,982 - ou seja, o município tem praticamente uma só propriedade, onde a área média trabalhada por pessoa ocupada na agricultura é de $7,41 \mathrm{~km}^{2}$ (ver Quadro 3). Evidentemente, isso não é um exemplo de desenvolvimento rural. Apenas como observação, o ITR recolhido pelo município de Telêmaco Borba representa apenas $0,6 \%$ da receita municipal, e antes que se diga que esse é um município com uma receita industrial importante, em outros municípios agrícolas a participação do ITR também é baixíssima. Em Sorriso (MT), o ITR participa com apenas $0,2 \%$ da receita municipal, e em Lucas do Rio Verde (MT), a participação é de apenas 1,5\% (dados de 2013). Nesse ponto deve-se levar em conta novamente a questão da sustentabilidade. A vulnerabilidade desses municípios diante de mudanças bruscas de conjuntura é muito grande. Um quebra de safra, uma variação mais acentuada para baixo nos preços das commodities ou mesmo o fechamento de uma instalação industrial pode provocar enormes problemas para as finanças municipais.

O caso recente do setor sucroalcooleiro também é representativo. Segundo estimativas do setor, do ano de 2008 a 2014, 66 unidades de produção encerraram as suas atividades. Muitas dessas usinas na realidade mal chegaram a funcionar'. Com isso, áreas particularmente vulneráveis em Goiás estão enfrentando sérios problemas de desemprego. O fechamento das usinas Canadá,

9. Ver http://www.unica.com.br/na-midia/11833239920328258727/ fechamento-de-usinas-aumenta-crise-no-setor/.
São Simão e Serra do Caipó em Goiás representaram a dispensa de 10 mil empregados em 2014, segundo o sindicato patronal ${ }^{10}$. Em um primeiro momento, os dados de arrecadação e repasses de ICMS do estado de Goiás para os municípios de Acreúna, São Simão e Montividiu, onde estão localizadas essas usinas, não registraram impactos relevantes, mesmo considerando os valores deflacionados ${ }^{11}$. Todavia, não há dúvida que a conta vai chegar e o governo federal será chamado para aumentar os limites de endividamento desses municípios.

Como foi demonstrado, há grande heterogeneidade entre os diversos tipos de agricultores no Brasil, mas isso não nos torna um caso especial no mundo. Todos os países, principalmente aqueles em desenvolvimento, demonstram grande heterogeneidade no setor rural e exatamente por esse motivo as políticas são diferenciadas segundo o tipo de clientela, não sendo possível trabalhar uma única política agrícola. Não é apenas o "gap" tecnológico que preocupa, mas também o "gap" no acesso aos serviços, no transporte e comercialização e nos rendimentos. Se o objetivo é alcançar o desenvolvimento rural e o fim da pobreza, para tanto, temos que trabalhar algumas políticas que possam facilitar a introdução de tecnologias mais adequadas e sustentáveis, assim como a construção de mercados para os produtos e serviços ofertados pelo campo.

\section{Políticas para a redução da heterogeneidade no campo}

Reduzir as distâncias sociais e econômicas entre produtores permite ampliar o alcance do desenvolvimento rural. A seguir, apresentam-se quatro reflexões sobre o desenvolvimento de políticas públicas diferenciadas, visando o atendimento de um público maior.

10. Jornal Cana. Ribeirão Preto. Edição no. 246, p. 16, julho de 2014.

11. Os valores foram obtidos no Portal da Frente Nacional de Prefeitos. No caso de Montevidiu, registra-se queda de mais de 50\% no repasse do ICM entre 2010 e 2013. 


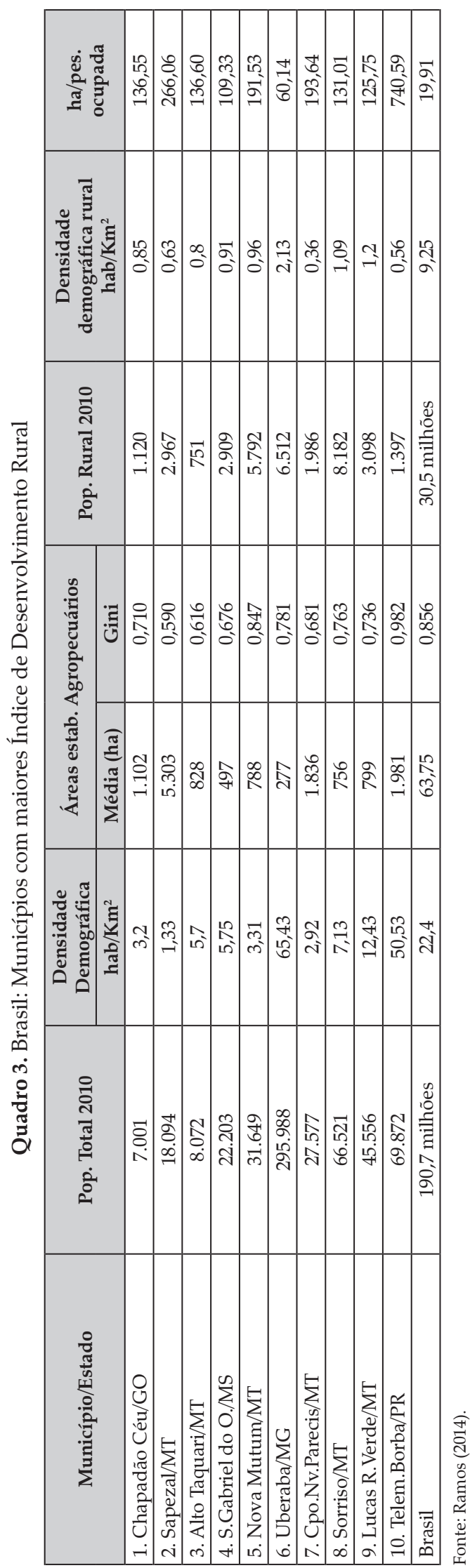

RESR, Piracicaba-SP, Vol. 53, № 01, p. 009-030, Jan/Mar 2015 - Impressa em Abril de 2015 


\subsection{Informação de mercado}

Segundo o Censo Demográfico, no Brasil, em 2010, apenas 8,5\% dos residentes no meio rural possuíam microcomputador e somente $4 \%$ tinham acesso à internet, mas as proporções para rádio e TV se elevaram bastante nos últimos anos e estão cada vez mais próximas do meio urbano. De fato, as principais mídias para comunicação com o trabalhador ou o empresário do campo são ainda os programas de rádio e TV. No entanto, devido à necessidade de uma comunicação mais ágil para a tomada de decisão quanto ao plantio ou às decisões de comercialização, os agricultores necessitam de outros instrumentos (RODRIGUES e RODRIGUEZ (coords.), 2013). O Censo Demográfico aponta que $61,1 \%$ dos moradores no meio rural têm telefones celulares. Trata-se de uma taxa até certo ponto alta e pouco aproveitada pelos organismos de extensão. Mas como é a política tarifária para quem está no campo? Sabemos que esta não é diferente daquela para os usuários das grandes cidades.

Um exemplo internacional do uso de celulares para informações para agricultores pode ser tirado de Bangladesh. Aproveitando a experiência do programa de microcréditos do Grameen Bank para Bangladesh, o Google está desenvolvendo um programa de telecomunicações para a África com informações úteis para o agricultor, como preços de mercado e comercialização, ações para a prevenção de pestes, pragas e doenças etc. ${ }^{12}$, via celular. O programa teve origem naquele país asiático a partir da proposta de empoderamento das comunidades e, por outro lado, do baixo interesse dos empreendedores da área de telecomunicações em atuar no meio rural. Com isso, o Grameen Bank criou uma companhia de telefonia celular, a Grameen Telecom que popularizou os negócios com telefone nas vilas. O banco investiu US\$ 1,2 bilhão em uma "joint venture" com uma companhia telefônica norueguesa e revolucionou o negócio com telecomunicações no país,

12. Ver http://www.google.com/earth/outreach/stories/grameen. html. com os custos da operação sendo divididos entre o banco, a companhia telefônica e o consumidor. As mulheres foram as grandes beneficiadas dessa tecnologia, e pesquisas mostram que, com essa tecnologia, foi possível resolver problemas práticos contornando dificuldades na negociação dos seus produtos e melhorando aspectos subjetivos com a autoestima (VINCENT e CULL, 2013). O modelo foi exportado para o Cambodja e para diversos países africanos, além da Colômbia. Os estudos mostram que os agricultores que receberam os "smartphones" conseguem preços mais elevados pela sua produção que os demais, acesso direto aos compradores (sem intermediários), redução de desperdício, entre outras vantagens (MEHTA, 2013; FAO, 2012).

\subsection{Extensão rural}

A extensão rural é fundamental para garantir a melhoria na produtividade e, mais do que isso, proporcionar melhor comercialização devido ao melhor acesso aos mercados. Um metaestudo recente, feito a partir de outros 289 casos, encontrou uma média do retorno financeiro calculado sobre os programas de extensão da ordem de 58\% (WORLD BANK, 2005:106). O problema, nesse caso, é garantir acesso dos produtores à extensão, uma vez que há enorme diferença na sua capacidade de articulação com os organismos e empresas que realizam esse serviço. Por exemplo, estabelecimentos dirigidos por mulheres têm menor acesso à extensão que os demais.

Em 2010, foi instituída a Lei das ATER, e em 2013 foi criada a ANATER no Brasil. É um novo modelo com pessoas jurídicas de Direito Privado e empresas públicas que, em parceria com a Embrapa, promovem atividades sem fins lucrativos. As novas organizações são selecionadas através de chamadas públicas e o governo federal tem demonstrado a intenção de gastar uma quantia razoável no desenvolvimento de projetos de extensão nos próximos anos. Esse é um modelo que foi bem-sucedido no México e vem para suprir uma lacuna decorrente do "apagão" dos serviços de assistência técnica nos anos 90 . 
No México, as ONGs e instituições locais comprovaram ter mais eficiência no desenvolvimento das tarefas de assistência técnica que as antigas organizações públicas ${ }^{13}$. Nesse modelo, as organizações locais têm o papel de facilitar a difusão de tecnologias misturando características locais com informações técnicas atualizadas. Já nos países andinos e em Cuba, em função da absoluta falta de recursos, se disseminou a assistência técnica direta baseada quase que totalmente nos conhecimentos tradicionais. Programas de visitas técnicas como o "Campesino a Campesino" hoje são as principais formas de extensão rural nesses países pobres. É certo que o conhecimento local não pode ser substituído pela tecnologia moderna, o chamado conhecimento científico, mas, evidentemente, eles são complementares e a pesquisa formal pode contribuir de diversas formas para o desenvolvimento rural.

Investir no capital humano é outro caminho para melhorar os rendimentos e a produtividade. Nesse sentido, as escolas de ensino básico no meio rural e as escolas técnicas agrícolas são de grande importância para o aprendizado e a capacitação. No Brasil, as estatísticas mostram uma grande defasagem idade-série e uma alta incidência de abandono de curso por parte das crianças e jovens que vivem nas áreas rurais. Há 70,8 mil escolas de educação básica localizadas nas áreas rurais. Segundo levantamento recente com base no Censo Escolar, nos últimos 10 anos, oito escolas por dia foram fechadas (BRASIL FECHA..., 2014). O problema é mais grave em áreas remotas e nos assentamentos. De acordo com o Incra, a população de estudantes assentados é de 980 mil, mas apenas 8.679 escolas atendem alunos residentes em assentamentos - considerando aquelas localizadas nos próprios assentamentos ou em seu entorno. Os dados são da década passada, extraídos do único levantamento realizado: a Pesquisa Nacional da Educação na Reforma Agrária (Pnera) de 2004, mas a realidade não deve ter mudado muito nos últimos anos.

13. Pesa (Programa Especial para La Seguridad Alimentaria). Sagarpa (Secretaría de Agricultura, Ganadería, Desarrollo Rural, Pesca y Alimentación - México).
Quanto ao ensino profissionalizante, vale frisar que o Senar (Serviço Nacional de Aprendizagem Rural), via escolas do Pronatec (Programa Nacional do Ensino Técnico), através de ensino à distância, têm papel importante, com mais de 50 cursos, mas os seus dados não são de acesso público e todas essas ações estão muito aquém do que se poderia fazer. Um exemplo internacional de destaque entre os países em desenvolvimento pode ser encontrado na Colômbia. O Sena (Servicio Nacional de Aprendizaje), entidade pública semelhante ao nosso Sistema " $\mathrm{S}$ ", realiza um trabalho de educação de massa formal pela via presencial ou à distância. Para se ter uma ideia da magnitude das suas atividades de capacitação, somente em 2013, na área rural, o Sena treinou quase 500.000 pessoas em cursos gratuitos de aprendizagem, empreendedorismo e formação de redes para a área rural e urbana. Esses cursos propiciaram, em 2013, a emancipação de 129 empresas incubadas ${ }^{14}$.

\subsection{Crédito Rural}

Segundo o Plano Safra 2014/15,o governo federal deverá disponibilizará R\$ 156,1 bilhões em recursos aos produtores rurais patronais, com crescimento de $14,7 \%$ sobre os R\$ 136 bilhões destinados para o período anterior, no País. Outros R\$ 24,1 bilhões estão sendo viabilizados para a agricultura familiar, com aumento equivalente em relação à safra passada. Esse volume de recursos obrigatórios recorde parece não ser problema e, segundo as lideranças do setor que participaram ativamente das discussões sobre o plano ${ }^{15}$, não há grandes reclamações quanto à quantidade de recursos obrigatórios colocados nas mãos dos produtores.

14. Ver http://www.sena.edu.co/transparencia/gestion-de-planeacion/Paginas/Informe-Estadistico.aspx

15. Conforme noticiado na página da Confederação Nacional de Agricultura (CNA). Ver www.canaldoprodutor.com. br/comunicacao/noticias/agropecuaria-tera-r-1561-bilhoes-do-governo-para-safra-20142015 e na página da Sociedade Nacional de Agricultura (SNA). Ver http://sna. agr.br/plano-safra-201415/ 
Apesar da abundância de recursos, é importante destacar que, segundo informações do Censo Agropecuário de 2006, menos de 20\% dos agricultores declararam ter acionado o crédito rural oficial e não oficial (BELIK, 2014). Não há explicação clara do porquê o acesso ao crédito rural é tão baixo. Segundo o Censo, entre os diversos motivos pelos quais os agricultores não acessaram o crédito rural, aparece como motivo principal "não precisou". O motivo "não precisou" foi evidenciado em $61,7 \%$ dos estabelecimentos da agricultura não familiar e em 50,1\% dos estabelecimentos da agricultura familiar. Ao contrário do esperado, o motivo "burocracia" para o não acesso ao crédito aparece com um percentual relativamente baixo, e a sua proporção na agricultura familiar é muito semelhante a encontrada na agricultura não familiar: respectivamente $8,4 \%$ e $8,1 \%$; muito embora, no caso dos assentados, essa cifra atinja respectivamente $15,0 \%$ e $14,5 \%$.

Há uma correlação entre crédito e aumento da produção, e vimos que o crédito é um elemento importante para alavancar a produtividade dos estabelecimentos. Todavia o crédito oficial não é a única fonte de recursos externos dos produtores. Certamente, muitos fazem uso de mecanismos alternativos como esquemas de "barter" com tradings ou via compra antecipada. Esses mecanismos não são reconhecidos pelo agricultor através do Censo Agropecuário, como modalidades de crédito e, certamente, a taxa de juros implícita nessas operações deve superar os 6,5\% a.a. do crédito oficial. Novos instrumentos estão sendo desenvolvidos pelo mercado financeiro para atender essa demanda por financiamento e também por papéis que possam alavancar o giro financeiro e o volume de títulos do agronegócio registrados na BM\&F e Cetip (empresa que oferece registro de títulos) é crescente. Em levantamento recente, Belik (2014) constatou que o estoque desses títulos já superava os R $\$ 30$ bilhões $^{16}$. Parece claro, portanto, a necessidade de repensar algumas estratégias de

16. Dados de 31/03/2012. financiamento para a produção, tornando mais acessível o crédito oficial e também democratizando os mecanismos de transferências de crédito privado. Estudos mostram que o custo da equalização da taxa de juros na política de crédito rural para o Tesouro Nacional com o Banco do Brasil é bastante elevado e haveria economia se o sistema fosse coordenado pelo BNDES, com maior participação dos bancos comerciais (CONTI e ROITMAN, 2011).

Vimos que, na parte de baixo da pirâmide de rendas, 6,2 milhões de pessoas ou 2,2 milhões de domicílios rurais estão abaixo da linha da pobreza de $\mathbf{R} \$ 70,00$ per capita / dia, segundo o Censo de 2010. Trata-se de um público prioritário para programas de microcrédito para investimentos - que, com exceção do Crediamigo (e Agroamigo, especificamente, para o Crédito Rural) do Banco do Nordeste (WORLD BANK, 2006), ainda não decolou no Brasil. Por outro lado, programas como o PAA e as compras da agricultura familiar para a alimentação escolar ${ }^{17}$ são um enorme sucesso. Em 2013, o programa beneficiou 63 mil produtores e, em 2014, ano que completa 10 anos de atividade, o orçamento deve superar R $\$ 1$ bilhão. No caso das compras da agricultura familiar para a alimentação escolar, outro R\$ 1 bilhão foi reservado pelo governo federal, em adição ao que tem sido disponibilizado pelos estados e municípios. Contudo, para esse programa, a adesão ainda é baixa, dada as dificuldades que esses agricultores estão tendo para regularizar a sua situação e os problemas burocráticos colocados pelas prefeituras para viabilizar a compra.

Na ausência de financiamento, informações compiladas pela PNAD mostram que muitos agricultores pobres com aposentadoria rural estão utilizando esses recursos não só para a sua manutenção como também para a produção. No Brasil, esses poucos recursos, que deveriam ser utilizados como colchão de proteção social, acabam sendo utilizados na produção por falta de outros instrumentos de crédito (DELGADO, 1997).

17. Lei Federal n. 11.947/2009. 


\subsection{Comercialização}

O caso da produção leiteira na Índia é paradigmático e vem sendo estudado como uma importante inovação no campo da comercialização (HLPE, 2013). A Índia possui o maior rebanho leiteiro do mundo, mas a sua produção até alguns anos atrás era incipiente. Através do gerenciamento de cooperativas, os indianos passaram a coletar o leite nas propriedades menores com produção de alguns poucos litros por dia. Rapidamente, a Índia passou a ser o maior produtor mundial de leite, produzindo perto de 100 milhões de toneladas, atividade essa que envolve 70 milhões de produtores (KENDA, 2009). Essa "revolução branca", como os indianos a denominam, já contribui com $17 \%$ da produção global de leite (somando-se leite de vaca com leite de búfala), muito embora apenas 35\% desse leite sejam processados. Ou seja, as cooperativas, em conjunto com diretrizes seguidas por uma política de Estado voltada para a melhoria da nutrição da população, incentivaram maior produção e produtividade, privilegiando circuitos curtos de distribuição.

Para entendermos a distribuição é preciso levar em conta todas as operações que vêm da porteira para fora. Esse é um gargalo importante, pois, como foi mencionado, trata-se de um inibidor das rendas muito importante. Temos que aperfeiçoar os sistemas de abastecimento para a comercialização e a distribuição dos produtos para o mercado interno e externo. Esses talvez sejam os fatores que provoquem maior diferenciação entre os agricultores. O chamado "gap" de comercialização se coloca ao lado do "gap" tecnológico como um dos desafios da política agrícola. Há também uma questão sistêmica: de nada adianta aumentar a produtividade do estabelecimento se não são promovidas ações visando à melhoria da infraestrutura e à inserção dessa produção nos mercados, seja por meio de cadeias curtas de fornecimento ou cadeias globais.

Disseminar tecnologias e coordenar a cadeia produtiva são tarefas complexas e os agentes que tomam essas iniciativas de produção conse- guem as maiores parcelas do Valor Adicionado nesse processo. No Brasil, costuma-se denominar esses agentes - que podem ser tradings, supermercados, a agroindústria ou outro qualquer - de "cabeça do canal". Na literatura estrangeira esses aparecem como "innovation brokers" e têm o papel de organizar a cadeia produtiva. O grande desafio e a dificuldade para esses agentes é organizar a oferta e a interação com os mercados em favor das partes mais vulneráveis. Quando esse trabalho não surge espontaneamente, pois não está ligado a preocupações comerciais imediatas, ele pode ser induzido pela política pública.

O Brasil está vivendo um fenômeno novo que é a constituição de empresas capitalistas produtoras na atividade agrícola. No passado, as empresas contratavam a produção para o seu processamento, comercialização interna ou exportação. Tivemos também um boom das empresas cooperativas, mas a entrada direta de empresas - muitas delas controladas por fundos de investimento, ou empresas de capital aberto diretamente na produção é recente. Empresas como a SLC, Los Grobo, Ceagro (agora Agrex controlada pelo Grupo Mitsubishi), Agrinvest, Tiba, Kobra etc. são novos agentes no espaço da agricultura brasileira. Segundo levantamento do jornal Valor Econômico, 10 empresas controlam a produção de mais de 1 milhão de hectares em Mapitoba ${ }^{18}$. Todas essas fazendas são integradas e muitas delas estão investindo em terminais próprios para o escoamento da sua produção diretamente para exportação.

Essa relação entre a produção local e a comercialização é delicada, ainda mais na conjuntura atual, em que as empresas comercializadoras estão se integrando para trás e incorporando as áreas de produção e processamento. $\mathrm{Na}$ década passada, muitas "tradings" internacionais de destaque entraram na área de produção e processamento no Brasil. Na área de açúcar e álcool, por exemplo, o chamado ABCD (ADM, Bunge, Cargill e Dreyfus), que controla quase $90 \%$ do

18. Ver "Megaprodutores consolidam a última fronteira", Valor Econômico, 01/04/2013. 
comércio global de grãos, instalou usinas e essas passaram a dominar o processo de produção de açúcar e álcool diretamente (MURPHY, BRUCH e CLAPP, 2009). Com a crise financeira de 2008, muitos desses investimentos recuaram e certas empresas refizeram as suas posições. A recente associação da Copersucar com a Cargill no açúcar mostra que a atividade de comercialização é cada vez mais uma atividade especializada e a estratégia passa por conhecer e controlar mais e melhor os circuitos internacionais.

No campo do abastecimento interno, apesar de todas as mudanças promovidas na política agrícola e de segurança alimentar e nutricional nas últimas décadas, quase nada foi feito no Brasil para aperfeiçoar o sistema de abastecimento. Muitos dirão que as grandes redes de supermercados podem se encarregar do varejo de alimentos com muita eficiência e, de fato, esses agentes são responsáveis por $80 \%$ do varejo de alimentos (de todo tipo) no Brasil ${ }^{19}$. Mas, por outro lado, temos um sistema atacadista com 76 centrais de abastecimento que poderiam disseminar a produção organizando os produtores, estabelecendo uma classificação geral para FLV, padronizando preços, exercendo as funções de plataforma logística para os pequenos produtores visando atender a demanda local e regional. O que se observa, contudo, é uma completa desarticulação dessas centrais (BELIK e WEGNER, 2012) e a irracionalidade do sistema no qual certas Centrais de Abastecimento, ao invés de terem um papel central na organização dos produtores locais, compram a maioria dos seus produtos a mais de 600 km de distância (CUNHA, 2013).

No caso de grãos, o sistema de armazenagem e estoques públicos também não vem funcionando bem como mecanismo estratégico de retenção do produto para a obtenção de melhores preços para os agricultores. $\mathrm{Na}$ realidade, existe um problema de armazenagem no Brasil tanto para a agricultura familiar como para os

19. Segundo pesquisa realizada pela CNA (Confederação Nacional da Agricultura) em 2011. Pesquisa Quantitativa/ Consumo de Frutas e Hortaliças. Brasil, 2011. Ver www. canaldoprodutor.com.br setores do agronegócio. No caso da agricultura familiar, por exemplo, um levantamento coordenado por Schneider e Xavier (2013) mostra que, no Nordeste, onde as necessidades são elevadas, há falta de uma ação mais firme para a construção de silos, o que acabou por provocar problemas graves para a pecuária durante os anos de seca, de 2011 a 2013. Segundo o Censo Agropecuário de 2006, havia apenas 13.879 silos forrageiros na região Nordeste, o que resulta em média de 0,08 por estabelecimento familiar do grupo B, o mais fragilizado com acesso ao Pronaf. Uma política de incremento de silagem é simples e barata e poderia ser lançada com facilidade ${ }^{20}$. A própria $\mathrm{FAO}$, em conjunto com o Banco Mundial, vem distribuindo silos pela África e Ásia a custos reduzidos, desde $1997^{21}$. É perfeitamente possível fazer um programa de silos da mesma maneira que vem caminhando o Programa 1 milhão de Cisternas (P1MC) para água na região do semiárido, que já construiu ou garantiu a autoconstrução de 500 mil cisternas com capacidade para 16 mil litros a

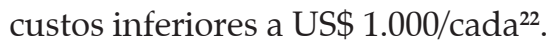

Vale mencionar que no caso das exportações, os silos de grande porte também representam uma lacuna. Nos novos terminais de exportação intermodais, as "tradings" estão usando recursos próprios para construir a infraestrutura dentro do regime de concessão e, pelo lado do governo, corre-se atrás do atraso com a aprovação recente de um RDC (Regime Diferenciado de Contratação) para o reforço no sistema de armazenagem pública.

20. Os silos comuns do tipo trincheira custam em torno de $\mathrm{R} \$ 1$ mil e podem estocar a forragem de um pequeno pecuarista por todo o período de seca, ou o equivalente a 180 toneladas (Informativo da Produção de Leite. Viçosa: UFV, Edição 301, Ano XXII, p.2, junho de 2014).

21. Ver a descrição dos programas e o balanço realizado em 2010 em http://www.fao.org/fileadmin/user_upload/ags/ publications/FAO_WB_ph_web.pdf

22. Ver http://www.asabrasil.org.br/Portal/Informacoes.asp? COD_MENU $=1150$. 


\section{Conclusão}

A heterogeneidade na agricultura brasileira não pode se caracterizar como um evento extraordinário a ser enfrentado por meio das políticas públicas. Como vimos ao longo desse texto, a heterogeneidade sempre esteve presente na agricultura brasileira mesmo durante os ciclos econômicos baseados em monoculturas de exportação, cujos produtos caracterizavam "a" agricultura brasileira. Da mesma maneira que a heterogeneidade está presente em outras agriculturas, sejam elas mais "tecnificadas" como a norte-americana, ou mais intensivas em mão de obra como aquelas dos países em desenvolvimento, essa característica nos acompanha ao longo da história. Todavia, muito embora a heterogeneidade seja um fenômeno comum a todas as agriculturas, a desigualdade é uma marca da agricultura brasileira.

A heterogeneidade (ou a diversidade) da agricultura brasileira compreende as diferentes formas de organização da produção, tamanhos de exploração e gestão da força de trabalho. Muito embora as receitas provenientes da produção e os ganhos líquidos decorrentes da exploração possam apresentar resultados diferentes, essa constatação per se não estabelece hierarquia ou superioridade de uma forma de organização da produção sobre outra. A questão principal que merece a atenção das políticas públicas é a desigualdade presente entre os produtores do meio rural no Brasil.

Embora a pobreza rural tenha se reduzido nos últimos anos, a sua proporção entre a população é algumas vezes maior que aquela observada no meio urbano. A pobreza rural e a falta de oportunidades têm como origem as diferentes condições de acesso desses residentes e produtores aos fatores de produção e a sua baixa capacidade no sentido que Amartya Sen dá para esse termo, de transformar a realidade. Tudo isso se traduz em baixa produtividade, rendimentos reduzidos e a renovação do ciclo de pobreza. O acesso restrito aos fatores de produção e o foco nas capacidades deveriam ser objeto de programas públicos que pudessem transformar a realidade do campo brasileiro. Para tanto, foram analisados quatro tipos de ação pública com efeitos imediatos para o combate à desigualdade e que poderiam ser desencadeadas de imediato em reforço à política agrícola, a saber:

a) Programas de assistência técnica que possam tirar benefício de novas tecnologias, como a telefonia celular, de forma a democratizar informações agronômicas, climatológicas, dos mercados e das oportunidades de comercialização;

b) Programas de extensão rural, treinamento e apoio ao agricultor e à sua família, de forma a ampliar o alcance da sua produção, considerando um movimento crescente que vai da produção para o autoconsumo, passa pelos mercados locais e regionais e pode chegar aos mercados nacionais.

c) Novos instrumentos de financiamento para o produtor que sejam mais flexíveis, garantindo, ao mesmo tempo, redução de burocracia para o produtor, possibilidades de formalização junto às instituições de crédito e, consequentemente, maior atratividade para os agentes privados.

d) Finalmente, uma atenção especial ao elo da comercialização na cadeia produtiva, pois é nessa etapa que se têm adicionado as maiores parcelas de valor ao produto da agropecuária e a política agrícola ainda atua de forma muito modesta, com poucas possibilidades de intervenção ou regulação.

Historicamente, já avançamos muito com o reconhecimento da agricultura familiar e também com a possibilidade de desenharmos políticas territoriais e regionais, mas precisamos aperfeiçoar ainda mais o modelo agrícola brasileiro. O reconhecimento do caráter heterogêneo do campo no Brasil e a adaptação de programas para as diferentes realidades é o caminho mais seguro para a promoção do desenvolvimento rural. 


\section{Referências bibliográficas}

ALKIRE, S. et al. Poverty in rural and urban areas - Direct comparisons using the global MPI 2014. Oxford: Oxford Poverty \& Human Development Initiative (OPHI). Oxford Department of International Development (ODID), 2014.

BELIERES, et al. Les agricultores familiales du mondedéfinitions, contributions et politiques publiques. Paris: CIRAD, 2014.

BELIK, W. O Financiamento da agropecuária no período recente. In: CALIXTRE, A. B., BIANCARELLI, A. M. e CINTRA, M. A. M. Presente e futuro do Desenvolvimento Brasileiro. Brasília: IPEA, 2014.

. e WEGNER, R. C. Distribuição de hortifruti no Brasil: papel das Centrais de Abastecimento e dos supermercados. Cuadernos Desarrollo Rural, Bogotá, v. 9, n. 69, p. 195-220, 2012.

BERNSTEIN, H. Food Sovereignty: A skeptical view. Food Sovereignty: A Critical Dialogue. International Conference, Yale University. Conference paper n. 1, 2013.

BRASIL FECHA em média, escola por dia na região rural. Folha de S. Paulo, 03/03/2014. < http://www1.folha. uol.com.br/educacao/2014/03/1420332-pais-fecha-oitoescolas-por-dia-na-zona-rural $>$. Acesso em: 15 jan. 2014.

CANO, W. Raízes da Concentração Industrial em São Paulo. 2. ed. São Paulo: T. A. Queiroz, 1981.

CATELA, E. S. e PORCILE, G. Heterogeneidade estrutural na produtividade das firmas brasileiras. Brasília, DF: CEPAL. Escritório no Brasil/IPEA, 2013 (Textos para Discussão CEPAL-IPEA, 55).

CHEN, S. e WANG, I. China's Growth and Poverty Reduction-Trends between 1990 and 1999. Washington: The World Bank, 2001 (World Bank Working Papers 2651).

CONTI, B. M. e ROITMAN, F. B. PRONAF: uma análise da evolução das fontes de recursos utilizadas no programa. Revista do BNDES, Rio de Janeiro, n. 35, p. 131-168, 2011.

CUNHA, A. R. A. A. Qual a ruralidade das Ceasas? Evidências sobre a inserção da agricultura familiar nas centrais de abastecimento brasileiras. 51o Encontro da Sober. Belém, PA, 2013.

DEAN, W. A industrialização de São Paulo. São Paulo: DIFEL, 1971.

DELGADO, G. Previdência rural: relatório de avaliação socioeconômica. Brasília: IPEA, 1997 (texto para discussão 477).
EUROPEAN COMMISSION. Other gainful activities: pluriactivity and farm diversification in EU-27. Bruxelas: European Commission - Directorate-general for agriculture and rural development, 2008.

FAN, C. C. e SUN, M. Regional inequality in China, 1978-2006. Eurasian Geography and Economics, v. 49, n. 1, p. 1-20, 2008

FAO - Food and Agriculture Organization. Mobile technologies for food security, agriculture and rural development - Role of the public sector. Roma: Food and Agriculture Organization of the United Nations, 2012.

FAO - Food and Agriculture Organization. The State of Food and Agriculture - Innovation in family farming. Roma: Food and Agriculture Organization of the United Nations, 2014.

FERREIRA, B. Reforma agrária: assentamentos rurais e segurança alimentar. Revista Política Social e Desenvolvimento, ano 2, n. 10, Campinas, p. 6-20, 2014.

FGV - FUNDAÇÃO GETULIO VARGAS; IBRE - INSTITUTO BRASILEIRO DE ECONOMIA. Quem produz o que no campo: quanto e onde II. Censo agropecuário 2006. Resultados: Brasil e regiões. Brasília: CNA, 2010.

FOLEY, J. A. et al. Solutions for a cultivated planet. Nature. v. 478, n. 10452, p. 337-342, 2011.

FURTADO, C. Desenvolvimento e subdesenvolvimento. Rio de Janeiro: Contraponto, 2009.

GASQUES, J. G., BASTOS, E. T., BACCHI, M. R. P. e VALDEZ, C. Produtividade total dos fatores e transformações da agricultura brasileira: análise dos dados dos censos agropecuários In: GASQUES, J. G., VIEIRA FILHO, J. E. R. e NAVARRO, Z. (Orgs.). A agricultura brasileira: desempenho, desafios e perspectivas. Brasília: IPEA, 2010.

., BASTOS, E. T., VALDEZ, C. e BACCHI, M. R. P. Produtividade da agricultura brasileira e os efeitos de algumas políticas. Revista de Política Agrícola, ano XXI, n. 3, p. 83-92, 2012.

GODFRAY, H. C. J. et al. Food Security: The Challenge of Feeding 9 Billion People. Science, v. 327, p. 812-818, 2010.

GUANZIROLI, C. E., BUAINAIN, A. M. e SABBATO, A. Dez anos de evolução da agricultura familiar no Brasil: 1996 e 2006. Revista de Economia e Sociologia Rural, Brasília, v. 50, n. 2, p. 351-370, 2012.

HELFAND, S. M. e DEL GROSSI, M. E. El boom agrícola y la pobreza rural en Brasil. In: GRAZIANO da SILVA, J., GÓMEZ, E. S. e CASTAÑEDA, S. R. (Eds.) 
Boom agrícola y persistencia de la pobre rural; estudio de ocho casos. Santiago do Chile: FAO-RLC, 2009.

HELFAND, S. e PEREIRA, V. Determinantes da pobreza rural e implicações para as políticas públicas no Brasil. In: BUAINAIN, A. M. et al. A nova cara da pobreza rural: desafios para as políticas públicas. Série Desenvolvimento Rural Sustentável, v. 16, Brasília: IICA, 2012.

HLPE - High Level Panel of Experts. Investing in smallholder agriculture for food security (High Level Panel of Experts on Food Security and Nutrition of the Committee on World Food Security), Roma, 2013

HOFFMANN, R. e NEY, M. G. Evolução recente da estrutura fundiária e propriedade rural no Brasil. In: GASQUES, J. G., VIEIRA FILHO, J. E. R. e NAVARRO, Z. (Orgs.). A Agricultura Brasileira: desempenho, desafios e perspectivas. Brasília: IPEA, 2010.

IBGE - INSTITUTO BRASILEIRO DE GEOGRAFIA E ESTATÍSTICA. Censo Agropecuário 2006. IBGE, 2006.

IFAD - International Fund for Agriculture Development. Smallholders, food security, and the environment. Roma: IFAD, 2013.

KAGEYAMA, A. (Coord.). O novo padrão agrícola brasileiro: do complexo rural aos complexos agroindustriais. In: DELGADO, G. C., GASQUES, J. C. e VILLA VERDE, C. M. (Orgs.). Agricultura e politicas públicas. Brasília: IPEA (Séria IPEA 127), 1990.

KAGEYAMA, A. A., BERGAMASCO, S. M. P. e AYAER de OLIVEIRA, J. Uma Tipologia dos Estabelecimentos Agropecuários do Brasil a partir do Censo de 2006. Revista de Economia e Sociologia Rural, v. 51, n. 1, p. 105122, jan/mar 2013

KENDA, C. Rural and Urban Linkages Operation Flood's Role in India's Dairy Development. Washington: IFPRI - International Food Policy Research Institute. IFPRI Discussion Paper 00924, 2009.

LEPORATI, M. et al. La agricultura familiar en cifras. In: SALCEDO. S. e GUZMÁN, L. (Eds.). Agricultura familiar en América Latina y el Caribe: recomendaciones de política. Santiago do Chile: FAO -RLC, 2014.

LONG, N. e PLOEG, J. V. Heterogeneidade, ator e estrutura: para a reconstituição do conceito de estrutura. In: SCHNEIDER, S. e GAZOLLA, M. (Orgs.). Os atores do desenvolvimento rural: perspectivas teóricas e práticas sociais. Porto Alegre: UFRGS Editora, 2011

MEHTA, B. S. Capabilities, costs, networks and innovations: impact of mobile phones in rural India. Institute for Human Development. Nova Delhi, India, 2013 (Working Paper 29).
MURPHY, S., BRUCH, D. e CLAPP, J. Cereal secrets -The world's largest grain traders and global agriculture. OXFAM Research Reports, 2009.

PAIM, G. Industrialização e economia natural. Rio de Janeiro: Iseb, 1957

PAIVA, R. M. Modernização e dualismo tecnológico na agricultura. Pesquisa e Planejamento Econômico, v. 1, n. 2, p. 171-234, 1971.

PIMENTEL, D. et al. Economic and environment benefits of biodiversity. BioScience, v. 47, n. 11, p. 747757, 1997.

PRADO JUNIOR, C. Formação do Brasil contemporâneo: colônia. 6. ed. São Paulo: Brasiliense, 1961.

RAMOS, P. Uma história sem fim: a persistência da questão agrária no Brasil contemporâneo. In: BUAINAIN, A.M et al. O mundo rural no Brasil do século 21- a formação de uma novo padrão agrário e agrícola. Brasília Embrapa, 2014.

RANGEL, I. Dualidade básica da economia brasileira. In: RANGEL, I. Obras Reunidas. Rio de Janeiro: Contraponto, 2005.

RAVAILLON, M. The idea of antipoverty policy. Cambridge, MA: National Bureau of Economic Research, 2013 (Working Paper 19210).

RAY, D., Mueller, N. D., West, P. C. e FOLEY, J. A. Yield Trends Are Insufficient to Double Global Crop Production by 2050. PLOS One, v. 6, n. 8, p. 1-8, 2013.

RODRIGUES, M. e RODRIGUEZ, A. (Coords.). Information and communication technologies for agricultural development in Latin America - Trends, barriers and policies. Santiago do Chile: CEPAL - Comissão Econômica das Nações Unidas para a América Latina, 2013.

SCHNEIDER, S. e CASSOL, A. A agricultura familiar no Brasil. Porto Alegre: RIMISP (Relatório de Pesquisa FIDA POBREZA Y DESIGUALDAD), 2013.

SCHNEIDER, S. e XAVIER, L. (Coord.). Caracterização do público potencial do PRONAF B na região Nordeste e no estado de Minas Gerais. Uma análise baseada nos dados do Censo Agropecuário 2006. Brasília: Ipea, 2013.

SCHNEIDER, S. e XAVIER, L. (Coord.). Caracterização do público potencial do PRONAF B na região Nordeste e no estado de Minas Gerais. Uma análise baseada nos dados do Censo Agropecuário 2006. Brasília: Ipea, 2013. (Relatório de Pesquisa).

SCHUH, G. E. Modernização e dualismo tecnológico na agricultura: Alguns Comentários. Pesquisa $e$ Planejamento Econômico, v. 3, n. 1, p. 51-94, 1973. 
SQUEFF, G. C. e NOGUEIRA, M. O. A Heterogeneidade estrutural no Brasil de 1950 a 2009. Brasília, DF: CEPAL. Escritório no Brasil/IPEA, 2013. (Textos para Discussão CEPAL-IPEA, 51).

VIEIRA FILHO, J E. R. e ROSA dos SANTOS, G. Heterogeneidade no setor agropecuário brasileiro: contraste tecnológico. Radar: tecnologia, produção e comércio exterior, Brasília, IPEA, n.14, p. 15-20, 2014.

VINCENT, K. e CULL, T. “Ten Seeds”: How mobiles have contributed to development in women-led farming cooperatives in Lesotho. Information Technologies $\mathcal{E}$ International Development, v. 9, n. 1, p. 37-48, 2013.

WORLD BANK. Agriculture investment sourcebook. Washington, DC: World Bank, 2005

. Meeting Development Challenges Renewed Approaches to Rural Finance. Washington, DC: World Bank, 2006.

ZEZZA, A. e LLAMBI, L. Meso-economic filters along the policy chain: Understanding the links between policy reforms and rural poverty in Latin America. World Development, v. 30, n. 11, nov. 2002, p. 1865-1884, 2002 